\title{
Downregulation of Arnt/ mRNA Expression in Women with Hypertension: A Case-Control Study
}

\author{
Zhengmei Fang $^{\mathrm{a}}$ Lijun Zhu $^{\mathrm{a}} \quad$ Yuelong Jin ${ }^{\mathrm{a}} \quad$ Yan Chen $^{\mathrm{a}}$ Weiwei Chang ${ }^{\mathrm{a}}$ \\ Yingshui Yao a, b \\ aDepartment of Epidemiology, School of Public Health, and Institute of Chronic Disease Prevention and Control, \\ Wannan Medical College, Wuhu, China; ${ }^{\text {} A n h u i ~ C o l l e g e ~ o f ~ T r a d i t i o n a l ~ C h i n e s e ~ M e d i c i n e, ~ W u h u, ~ C h i n a ~}$
}

\section{Keywords}

Essential hypertension - Aryl hydrocarbon receptor nuclear translocator like $\cdot$ Clock circadian regulator $\cdot$ Period circadian regulator 1 . Period circadian regulator 2

\begin{abstract}
Background: Previous studies have reported that disturbance of endogenous circadian rhythms enhances the chance of hypertension and suggested that circadian clock genes could have a crucial function in the onset of the disease. This case-control study was aimed to investigate the association of the mRNA expression of aryl hydrocarbon receptor nuclear translocator like (Arntl), clock circadian regulator (Clock), and period circadian regulators 1 and 2 (Per1 and Per2) with hypertension and blood pressure levels. Methods: A total of 172 subjects were recruited in this study, including 86 hypertension and 86 nonhypertension controls. The mRNA expression levels in peripheral blood mononuclear cells were determined by real-time quantitative polymerase chain reaction. The differences in Arntl, Clock, Per1, and Per2 mRNA expression were compared between the 2 groups, and the relationship between mRNA expres-
\end{abstract}

karger@karger.com www.karger.com/kbr

Karger $\stackrel{\text { ' }}{5}$

马OPEN ACCESS
(C) 2021 The Author(s)

Published by S. Karger AG, Basel

This is an Open Access article licensed under the Creative Common Attribution-NonCommercial-4.0 International License (CC BY-NC) (http://www.karger.com/Services/OpenAccessLicense), applicable to the online version of the article only. Usage and distribution for commercial purposes requires written permission. sion and cardiometabolic risk profiles was also assessed. $\boldsymbol{R e}$ sults: We found that the mRNA expression of Arntl was downregulated in the hypertension cases compared with controls in women $(1.10[0.66,1.71]$ vs. $1.30[0.99,2.06], p=$ $0.031)$. There was a significant negative correlation between the Arntl mRNA expression and SBP $(r=-0.301, p=0.004)$ and $\operatorname{DBP}(r=-0.222, p=0.034)$ in women. In men, a negative correlation between the Per 1 mRNA expression and SBP $(r=$ $-0.247, p=0.026)$ was found. Conclusions: The Arntl mRNA expression may play an important role in progression of hypertension in women. (c) 2021 The Author(s)

Published by S. Karger AG, Basel

\section{Introduction}

Hypertension is one of the most common chronic diseases with an increasing prevalence; moreover, it is a major risk factor for cardiovascular diseases, such as stroke and coronary heart disease [1]. About 9.4 million people

Zhengmei Fang, Lijun Zhu, and Yuelong Jin contributed equally to the work.

Correspondence to:

Yingshui Yao, yingshuiyao@ 126.com 
die because of hypertension each year across the world [2]. The results of the 2017 Global Burden of Disease study showed that hypertension is still the first risk factor contributing to the global burden of the disease [3]. The etiology and pathogenesis of hypertension remains unclear and is generally accepted as a result of the interaction of environmental and genetic factors. Previous studies have shown that the aryl hydrocarbon receptor nuclear translocator like (Arntl, also known as BMAL1) rs6486121 and clock circadian regulator (Clock) T3111C were associated with susceptibility to hypertension $[4,5]$. As per Kurbatova et al. [6], T3111C can affect the mRNA transcription level of Clock.

Clock and Arntl belong to the core components of circadian rhythm genes. Studies have shown that the pathological processes of many chronic diseases, such as insulin-dependent diabetes [7], obesity [8], and cardiovascular diseases [9], are accompanied by disturbances in the transcriptional activity of circadian rhythm genes. Rat experiments have shown that the blood pressure increased in TGR(mREN-2)27 rats, accompanied by a significant increase in Arntl expression [10]. Compared to that in Wistar rats, the expression of Clock increased in spontaneous hypertensive rats [11]. Another mice experiment showed a contradictory result; when a comparison was made with male wild-type mice, Clock knockout mice showed no variation in the blood pressure rhythm at 24 $\mathrm{h}$; however, there was a drop in the blood pressure levels [12]. In animal research studies, Clock mutant mice showed an elevated blood pressure and the clock protein period 1 (Per 1)-knockout female mice are protected from nondipping hypertension [13-15]. Per1 and Per2 are the target genes of the heterodimeric complex formed by Clock and Arntl. An increasing number of epidemiological studies have shown an association between circadian rhythm genes and hypertension $[4,5]$. Li et al. [16] found that hypertensive patients with the $\mathrm{C}$ allele of Clock T3111C or the GG genotype of Arntl A1420G may be more likely to develop high nighttime systolic blood pressure (SBP). In metabolic syndrome patients, Per2 was found to be linked to the risk factors [17]. rs6431590 in Per2 was independently associated with the presence of nondippers in hypertensive subjects [18].

These results suggest that Arntl, Clock, Per1, and Per2 may be involved in the development of hypertension. However, the results were mainly derived from animal models and focused on single locus variation. Therefore, the present study was designed as a case-control design to assess the relationship between Arntl, Clock, Perl, and Per 2 mRNA expression levels and hypertension.

\section{Methods}

\section{Study Subjects}

A total of 172 subjects with a mean age of 69.00 years $(64.00$ 80.00 years) were included in this case-control study, including 86 controls and 86 patients with hypertension. The hypertensive subjects and the control subjects were from the health examination group from the hospital medical examination center between July 2019 and August 2019. Inclusion criteria for cases: hypertensive status, age $>50$ years, regularity of life, and untreated hypertension. Exclusion criteria for cases: secondary hypertension; other serious cardiovascular and cerebrovascular diseases, such as coronary heart disease, stroke, and cardiac infarction; and jet lag or nightshift in the previous 2 weeks. Inclusion criteria for the control: the mean SBP $<140 \mathrm{~mm} \mathrm{Hg}$ and diastolic blood pressure (DBP) $<90$ $\mathrm{mm} \mathrm{Hg}$ in 3 blood pressure measurements and no history of hypertension, no cardio-cerebrovascular disease, residing in the same region as the patient; and age $>50$ years. The study procedures were approved by the Scientific Research IRB of Wannan Medical College Yijishan Hospital, and written informed consent was obtained from all the study subjects.

\section{Physical Examinations}

SBP and DBP were measured 3 times at a 1-min interval using an Omron electronic sphygmomanometer in a seated position after the subjects had rested well for $10 \mathrm{~min}$ after their blood was drawn, and their average value was obtained for the analysis. Hypertension was defined as SBP $\geq 140 \mathrm{~mm} \mathrm{Hg}$ and/or DBP $\geq 90 \mathrm{~mm}$ $\mathrm{Hg}$. Anthropometric variables (height and weight) were measured when the subject was wearing socks or was bare feet in the standing position using an ultrasonic height and weight meter (HGM 800A; Shengyuan Company, China). BMI was calculated as body weight in kilograms divided by the square of the body height in meters $\left(\mathrm{kg} / \mathrm{m}^{2}\right)$. Waist circumference was measured $1 \mathrm{~cm}$ above the umbilicus in a horizontal plane by using a general tape.

\section{Laboratory Measurements}

Blood samples were obtained from participants at about 9:00 a.m. after $10 \mathrm{~h}$ of overnight fasting. The following biochemical indicators were assessed: fasting blood glucose (FBG), total cholesterol (TC), triacylglycerol (TG), high-density lipoprotein cholesterol (HDL-C), and low-density lipoprotein cholesterol (LDL-C). The biochemical indicators were determined using an enzymatic method by the physical examination institution.

\section{RNA Extraction and Quantitative Real-Time Polymerase}

\section{Chain Reaction}

Total RNA was extracted from PBMCs using the TRIzol reagent (Invitrogen, USA) according to the manual instructions. Quality and concentration of RNA was evaluated using the NanoDrop 2000 spectrophotometer (Thermo Scientific, Wilmington, DE, USA). Reverse transcription of mRNA was synthesized using TAKARA PrimeScript RT reagent Kit (RR036A; Takara, Tokyo, Japan). The qRT-PCR reactions were performed with the Platinum SYBR Green Mix (Invitrogen, USA) and QuantStudio ${ }^{\mathrm{TM}} 7$ Flex Real-Time system (Applied Biosystems, Waltham, MA, USA). GAPDH was regarded as the endogenous control for mRNA. The relative expression of mRNA was calculated using the $2^{-\Delta \Delta \mathrm{Ct}}$ method. $2^{-\Delta \Delta \mathrm{Ct}}(\Delta \Delta \mathrm{Ct}$ case $=\Delta \mathrm{Ct}$ case $-\Delta \mathrm{Ct}$ control average value, $\Delta \Delta \mathrm{Ct}$ control $=\Delta \mathrm{Ct}$ control $-\Delta \mathrm{Ct}$ control average value, and 
Table 1. Demographic and clinical characteristics between hypertension and controls

\begin{tabular}{|c|c|c|c|c|}
\hline & $\begin{array}{l}\text { Control } \\
(n=86)\end{array}$ & $\begin{array}{l}\text { Hypertension } \\
(n=86)\end{array}$ & $x^{2} / Z / t$ & $p$ value \\
\hline \multicolumn{5}{|l|}{ Gender } \\
\hline Male & $41(50.6)$ & $40(49.4)$ & 0.023 & 0.879 \\
\hline Female & $45(49.5)$ & $46(50.5)$ & & \\
\hline Age, years & $69.00(64.00-80.00)$ & $69.00(64.00-79.00)$ & 0.424 & 0.671 \\
\hline \multicolumn{5}{|l|}{ Blood pressure, $\mathrm{mm} \mathrm{Hg}$} \\
\hline SBP & $124.24 \pm 9.71$ & $157.09 \pm 16.85$ & 15.664 & $<0.001$ \\
\hline DBP & $70.73 \pm 7.85$ & $82.98 \pm 9.55$ & 9.186 & $<0.001$ \\
\hline $\mathrm{BMI}, \mathrm{kg} / \mathrm{m}^{2}$ & $23.60 \pm 3.30$ & $24.51 \pm 3.13$ & 1.851 & 0.066 \\
\hline Waist circumference, $\mathrm{cm}$ & $80.14 \pm 8.97$ & $82.73 \pm 8.58$ & 1.938 & 0.054 \\
\hline $\mathrm{TC}, \mathrm{mmol} / \mathrm{L}$ & $4.92 \pm 0.81$ & $5.21 \pm 1.11$ & 1.937 & 0.055 \\
\hline $\mathrm{TG}, \mathrm{mmol} / \mathrm{L}$ & $1.22(0.42-5.62)$ & $1.37(0.51-6.03)$ & 1.818 & 0.069 \\
\hline $\mathrm{LDL}-\mathrm{C}, \mathrm{mmol} / \mathrm{L}$ & $2.69 \pm 0.64$ & $2.98 \pm 0.85$ & 2.546 & 0.012 \\
\hline $\mathrm{HDL}-\mathrm{C}, \mathrm{mmol} / \mathrm{L}$ & $1.42 \pm 0.41$ & $1.39 \pm 0.34$ & 0.542 & 0.589 \\
\hline $\mathrm{FBG}, \mathrm{mmol} / \mathrm{L}$ & $5.31(4.41-7.51)$ & $5.35(4.31-10.75)$ & 0.879 & 0.379 \\
\hline \multicolumn{5}{|l|}{ Smoking } \\
\hline Yes & $18(20.9)$ & $35(40.7)$ & 7.881 & 0.005 \\
\hline No & 68 (79.1) & $51(59.3)$ & & \\
\hline \multicolumn{5}{|l|}{ Drinking } \\
\hline Yes & $9(10.5)$ & $20(23.3)$ & 5.019 & 0.025 \\
\hline No & $77(89.5)$ & 66 (76.7) & & \\
\hline
\end{tabular}

Data are presented as $n$ (\%) or median (minimum-maximum) or mean \pm standard deviation. SBP, systolic blood pressure; DBP, diastolic blood pressure; BMI, body mass index; TC, total cholesterol; TG, triacylglycerol; HDL-C, highdensity lipoprotein cholesterol; LDL-C, low-density lipoprotein cholesterol; FBG, fasting blood glucose.

$\triangle \mathrm{Ct}=\mathrm{Ct}$ target gene $-\mathrm{Ct} G A P D H)$. The primer sequences used for qPCR were as follows:

1. Arntl: 5'-TGCAACGCAATGTCCAGGAA-3' (forward), 5'-GGTGGCACCTCTTAATGTTTTCA-3' (reverse)

2. Clock: 5'-TGCGAGGAACAATAGACCCAA-3' (forward), $5^{\prime}$-ATGGCCTATGTGTGCGTTGTA-3' (reverse)

3. Per1: $5^{\prime}$-GCCAACCAGGAATACTACCAGC-3' (forward), $5^{\prime}$-GTGTGTACTCAGACGTGATGTG-3' (reverse)

4. Per2: 5'-GACATGAGACCAACGAAAACTGC-3' (forward), 5'-AGGCTAAAGGTATCTGGACTCTG-3' (reverse)

5. GAPDH: 5'-GGAGCGAGATCCCTCCAAAAT-3' (forward), $5^{\prime}$-GGCTGTTGTCATACTTCTCATGG-3' (reverse)

Statistical Analysis

Continuous variables were tested for normality using the Kolmogorov-Smirnov test and expressed by means \pm standard deviation if normally distributed or the median and interquartile range for the skew distributional data. The $t$ test and Mann-Whitney $\mathrm{U}$ tests were used to test their differences, respectively. Categorical variable distributions between cases and controls were compared by the $\chi^{2}$ test. Correlation analysis between Arntl, Clock, Per1, and Per 2 and continuous variables of cardiometabolic risk profiles was assessed by the Spearman correlation coefficient test. Association analysis in the case-control study used logistic regression, and odds ratio and its 95\% confidence interval were calculated. Statistical analyses were performed using the SPSS version 18.0 (SPSS, Inc., Chicago, IL, USA). We considered results to be statistically significant when a 2 -tailed $p$ value of 0.05 was defined.
Table 2. Comparison of mRNA expression of Arntl, Clock, Per1, and Per2 between hypertension and controls

\begin{tabular}{lllll}
\hline & $\begin{array}{l}\text { Controls } \\
(n=86)\end{array}$ & $\begin{array}{l}\text { Hypertension } \\
(n=86)\end{array}$ & $Z$ & $p$ value \\
\hline Arntl & $1.05(0.66,1.63)$ & $0.88(0.55,1.28)$ & 1.776 & 0.076 \\
Clock & $0.99(0.61,1.67)$ & $0.94(0.52,1.52)$ & 0.913 & 0.361 \\
Per1 & $0.98(0.56,1.68)$ & $0.88(0.51,1.36)$ & 1.286 & 0.198 \\
Per2 & $1.08(0.65,1.80)$ & $1.14(0.51,1.88)$ & 0.006 & 0.995 \\
\hline
\end{tabular}

\section{Results}

\section{Clinical Characteristics of Participants}

There was no significant difference in the age, sex, BMI, waist circumference, total cholesterol, triacylglycerol, high-density lipoprotein cholesterol, and fasting blood glucose between the 2 groups $(p>0.05)$. However, the levels of SBP, DBP, LDL-C, smoking, and drinking proportion were higher in the hypertension group than those in the control group $(p<0.05)$. The data are shown in Table 1. 
Table 3. Gender subgroup of comparison of Arntl, Clock, Per1, and Per2 mRNA expression in 2 groups

\begin{tabular}{|c|c|c|c|c|c|c|c|c|}
\hline & \multicolumn{4}{|l|}{ Men } & \multicolumn{4}{|l|}{ Women } \\
\hline & $\begin{array}{l}\text { controls } \\
(n=41)\end{array}$ & $\begin{array}{l}\text { hypertension } \\
(n=40)\end{array}$ & $Z$ & $p$ value & $\begin{array}{l}\text { controls } \\
(n=45)\end{array}$ & $\begin{array}{l}\text { hypertension } \\
(n=46)\end{array}$ & $Z$ & $p$ value \\
\hline Arntl & $0.77(0.53,1.21)$ & $0.73(0.50,1.09)$ & 0.236 & 0.813 & $1.30(0.99,2.06)$ & $1.10(0.66,1.71)$ & 2.159 & 0.031 \\
\hline Clock & $0.66(0.40,0.86)$ & $0.62(0.42,0.94)$ & 0.293 & 0.770 & $1.41(1.02,2.47)$ & $1.35(0.77,1.96)$ & 1.278 & 0.201 \\
\hline Per1 & $0.97(0.53,1.58)$ & $0.75(0.46,1.30)$ & 0.982 & 0.326 & $1.22(0.72,1.71)$ & $0.97(0.62,1.45)$ & 0.841 & 0.400 \\
\hline Per2 & $0.90(0.48,1.72)$ & $0.90(0.48,1.73)$ & 0.059 & 0.953 & $1.14(0.79,1.95)$ & $1.34(0.54,1.92)$ & 0.040 & 0.968 \\
\hline
\end{tabular}

The mRNA Expression Levels of Arntl, Clock, Per1, and Per2 in the 2 Groups

Expressions of mRNA for Arntl, Clock, Per1, and Per2 did not differ significantly between the groups $(p>0.05$, Table 2). Subgroup analysis showed that the Arntl mRNA levels in PBMCs from the hypertension group were significantly lower than those from the control group in women ( $p=0.031$, Fig. 1$)$. However, similar results were not found in men. For Clock, Per1, and Per2 mRNA levels, no significant difference was found between the groups in women or in men. The data are presented in Table 3.

\section{Correlation between Arntl, Clock, Per1, and Per2}

\section{$m R N A$ Expression and Clinical Variables}

In women, the Arntl mRNA expression was negatively correlated with SBP levels $(r=-0.301, p=0.004)$ and DBP levels ( $r=-0.222, p=0.034)$; in men, Per1 mRNA expression was negatively correlated with the SBP levels $(r=$ $-0.247, p=0.026$; Fig. 2). In addition, the Per 2 mRNA expression was positively correlated with the LDL-C levels in women $(r=0.223, p=0.033)$. There were no correlations between the other clinical variables and the expression of mRNA for particular genes. The data are presented in Table 4 and online suppl. Figures 1 and 2 (see www.karger.com/doi/10.1159/000518669 for all online suppl. material).

\section{Discussion}

The circadian rhythm system is an important regulator of blood pressure circadian rhythm. The blood pressure of healthy people can reduce by $10 \%-20 \%$ at night and rise in the morning, which plays a crucial role in maintaining human health. Studies have shown that, compared with that at other times, during the morning blood pressure fluctuations, the risk of acute myocardial infarction is higher by $40 \%$, that of sudden cardiac death is increased by $29 \%$, and that of stroke is higher by $49 \%$

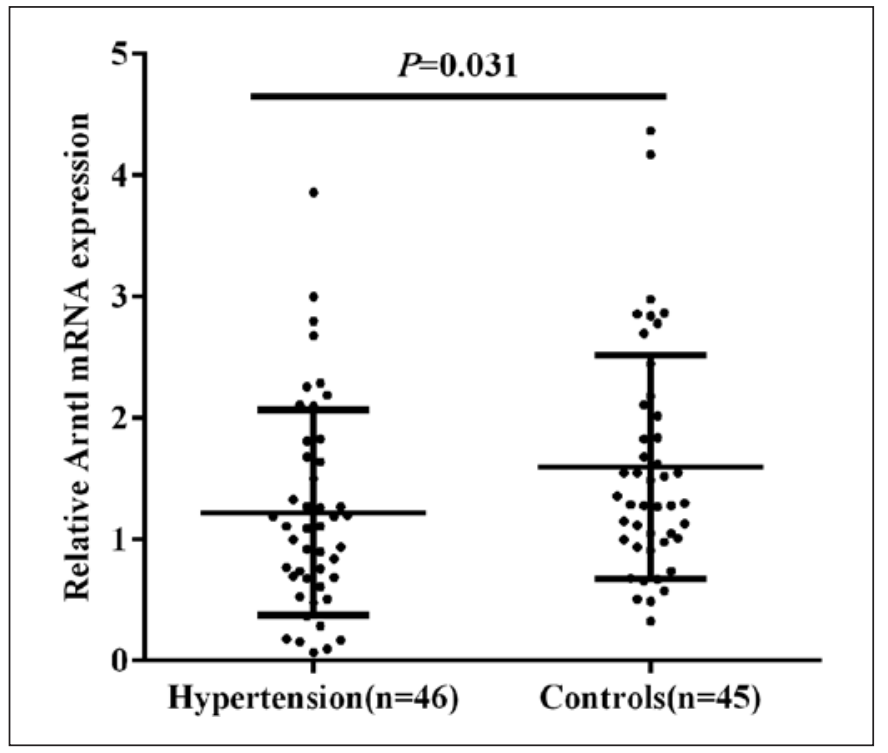

Fig. 1. Downregulation of Arntl mRNA expression in hypertension. Arntl mRNA levels are lower in hypertensives than in controls $(p=0.031)$. The dots represent individual relative mRNA expression level. The longest line represents the median, and the whiskers represent the interquartile range. Gene expression was measured using RT-PCR, with values normalized to GAPDH mRNA expression. Arntl, aryl hydrocarbon receptor nuclear translocator like.

[19-21]. Recent trials have shown that loss of Arntl, Clock, Per1, and Per2 function is closely associated with increased blood pressure.

In the present study, the results demonstrated a potential role of Arntl in blood pressure regulation. Compared to that in control women, the expression of Arntl was reduced in the PBMCs from women with hypertension. Moreover, correlation analysis indicated that the Arntl mRNA expression was negatively correlated with the SBP and DBP values. It is worth mentioning that few studies have reported the Arntl mRNA transcription levels. Genetic evidence has mainly focused on locus variation. Woon et al. [22] showed 
that 2 Arntl haplotypes were associated with hypertension. $\mathrm{Li}$ et al. [16] found that hypertensive patients with the GG genotype of Arntl A1420G may be more likely to develop high nighttime SBP levels. Recent genome-wide association studies have identified an association between Arntl SNPs rs9633835 and hypertension [23]. Peng et al. [5] have provided strong evidence showing that rs6486121 variants in Arntl are associated with hypertension. These data strongly support that Arntl is a plausible candidate gene for the development of hypertension.

Previous studies have shown that many factors, such as age and sex, may affect the expression of rhythm genes $[24,25]$. Animal experiments have demonstrated that the sex-based differences in the circadian clock gene expression could be attributed to sex hormones [26-28]. It is well known that variations exist at the molecular, cellular, and tissue levels between the sexes, contributing to the sex-specific differences in hypertension [29]. We speculated that the role of Arntl in blood pressure regulation may be influenced by patient sex and performed analyses stratified by sex. We further found in the present study that a sex-based difference existed in the association of Arntl and hypertension, which confirmed the hypothesis.

Evidence suggested that Arntl knockout mice showed dysfunction of endothelial nitric oxide synthase (eNOS) coupling and conversion and increased eNOS uncoupling and abnormal expression of related endothelial regulatory genes, resulting in increased peroxide and endothelial damage [30]. Shang et al. [31] reported that the sensitivity of Arntl mutant mice to vascular changes decreased, and the normal rhythmic expression patterns of the endothelial function regulator serine protein kinase and eNOS disappeared, leading to endothelial dysfunction. Further, knockout of mice Arntl led to endotheliumdependent vasodilation function reduction [14]. This process may involve the reduction of nitric oxide production, resulting in vascular endothelial function damage and vascular remodeling, eventually leading to blood pressure regulation disorder. Therefore, Arntl might play an important role in blood pressure regulation. The results of this study further suggest that downregulated mRNA expression of Arntl in the population may be related to the development of hypertension.

Per1 and Per2 are the target genes for the formation of the heterodimers of Clock and Arntl. We did not find a significant difference in the Per 1 and Per2 mRNA expression of hypertensive patients and controls; however, we observed a negative correlation between the expression level of Per 1 and SBP levels in men. Douma et al. [32] confirmed that under the condition of high salt intake, Per1 gene
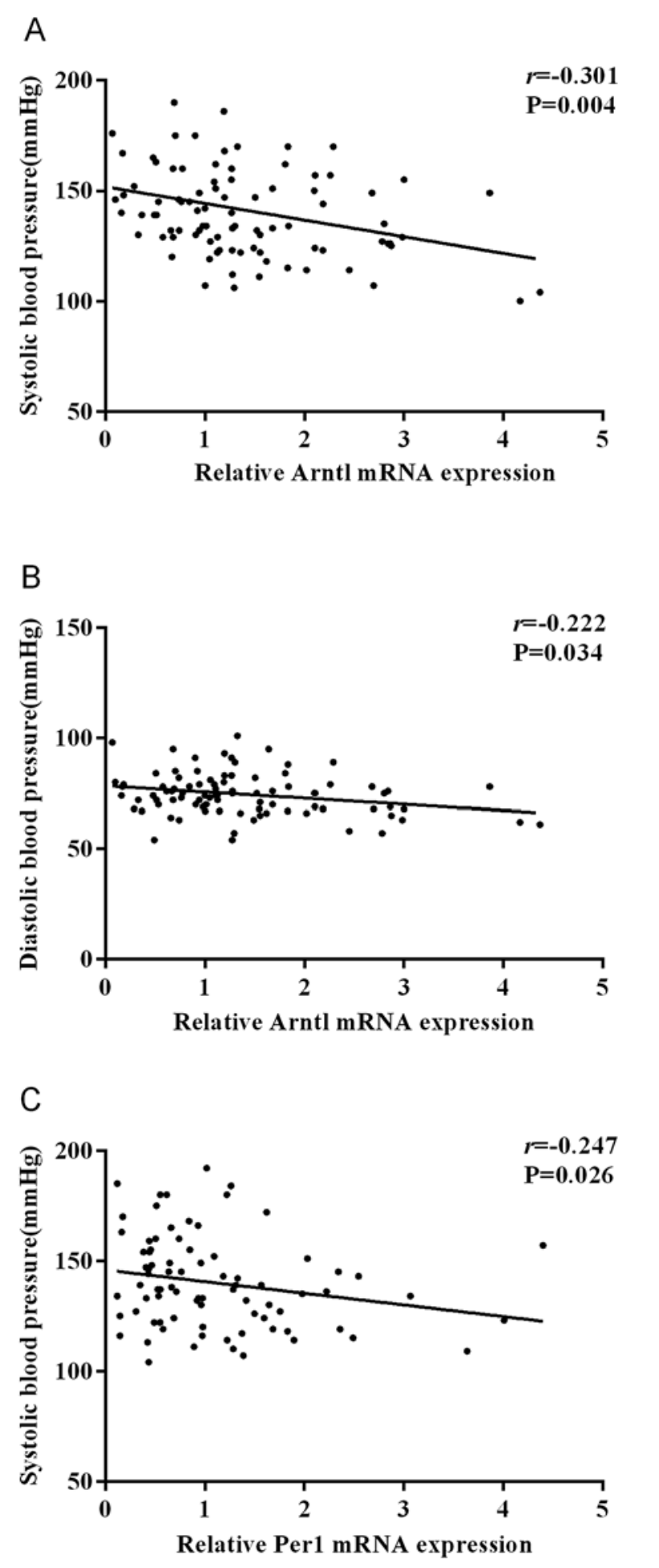

Fig. 2. Scatter plot of correlations between gene mRNA expression and arterial blood pressure. Correlations between Arntl and arterial blood pressure in women (A, B); correlations between Per1 and systolic blood pressure in men (C). Arntl, aryl hydrocarbon receptor nuclear translocator like; Per1, period circadian regulator 1 . 
Table 4. Correlation between mRNA expression and cardiometabolic risk profiles

\begin{tabular}{|c|c|c|c|c|c|c|c|c|}
\hline & \multicolumn{2}{|l|}{ Arntl } & \multicolumn{2}{|l|}{ Clock } & \multicolumn{2}{|l|}{ Per1 } & \multicolumn{2}{|l|}{ Per2 } \\
\hline & $r$ & $p$ value & $r$ & $p$ value & $r$ & $p$ value & $r$ & $p$ value \\
\hline \multicolumn{9}{|l|}{ Men } \\
\hline SBP & -0.105 & 0.350 & -0.179 & 0.109 & -0.247 & 0.026 & -0.119 & 0.294 \\
\hline DBP & -0.021 & 0.852 & -0.053 & 0.639 & -0.194 & 0.083 & 0.044 & 0.700 \\
\hline BMI & -0.016 & 0.890 & 0.043 & 0.703 & -0.174 & 0.120 & 0.076 & 0.506 \\
\hline WC & 0.038 & 0.736 & 0.012 & 0.919 & -0.216 & 0.053 & 0.097 & 0.396 \\
\hline $\mathrm{TC}$ & -0.204 & 0.067 & -0.188 & 0.093 & 0.049 & 0.666 & -0.059 & 0.603 \\
\hline TG & -0.062 & 0.581 & 0.000 & 1.000 & -0.116 & 0.304 & 0.078 & 0.493 \\
\hline LDL-C & -0.101 & 0.370 & -0.140 & 0.212 & 0.076 & 0.499 & -0.032 & 0.779 \\
\hline HDL-C & -0.138 & 0.218 & -0.073 & 0.515 & 0.001 & 0.991 & -0.090 & 0.429 \\
\hline FBG & -0.090 & 0.425 & -0.047 & 0.676 & 0.062 & 0.583 & 0.022 & 0.851 \\
\hline \multicolumn{9}{|l|}{ Women } \\
\hline SBP & -0.301 & 0.004 & -0.160 & 0.129 & -0.164 & 0.121 & -0.010 & 0.925 \\
\hline DBP & -0.222 & 0.034 & -0.131 & 0.217 & -0.132 & 0.211 & -0.030 & 0.780 \\
\hline BMI & -0.098 & 0.356 & 0.037 & 0.728 & -0.005 & 0.959 & 0.033 & 0.754 \\
\hline WC & -0.071 & 0.503 & 0.051 & 0.631 & -0.025 & 0.812 & -0.059 & 0.580 \\
\hline $\mathrm{TC}$ & -0.017 & 0.875 & -0.110 & 0.300 & 0.038 & 0.719 & 0.183 & 0.082 \\
\hline TG & 0.018 & 0.864 & 0.081 & 0.447 & 0.126 & 0.234 & 0.092 & 0.388 \\
\hline LDL-C & 0.087 & 0.410 & -0.073 & 0.493 & 0.106 & 0.318 & 0.223 & 0.033 \\
\hline HDL-C & -0.113 & 0.288 & -0.101 & 0.341 & -0.192 & 0.069 & -0.042 & 0.695 \\
\hline FBG & -0.110 & 0.300 & -0.109 & 0.302 & 0.033 & 0.758 & 0.002 & 0.984 \\
\hline
\end{tabular}

SBP, systolic blood pressure; DBP, diastolic blood pressure; BMI, body mass index; TC, total cholesterol; TG, triacylglycerol; HDL-C, high-density lipoprotein cholesterol; LDL-C, low-density lipoprotein cholesterol; FBG, fasting blood glucose.

knockout mice showed a significant increase in the mean arterial pressure, and Per1 showed sex-based dependence in the regulation of cardiovascular rhythm. Male mice mainly showed nondipper hypertension, while a protective effect on nondipper hypertension mediated by Perl was observed in female mice [13]. Moreover, the dysfunction of the circadian function can induce angiotensin II-dependent hypertension in mice [33]. Research has shown that mice that lack Per 1 exhibit significantly negatively regulated expression of $E d n 1$ that could be a vasoconstrictor peptide and with hypertension $[34,35]$. Kurbatova et al. [6] observed a temporal change of Per $1 \mathrm{mRNA}$ level during the day in hypertensive patients. Marques et al. [36] revealed that Per1 mRNA expressed in hypertensives renal medulla was higher than that in normotensives. However, human data on the role of Per 1 levels in PBMCs in the development of hypertension are lacking. Although we observed a negative correlation between Perl and SBP in men, the $r$ value was only -0.247 . Therefore, it remains unclear whether Perl is implicated in the pathogenesis of hypertension.

Studies have shown that compared with male wildtype mice, Clock knockout mice had no variety in blood pressure rhythm at $24 \mathrm{~h}$, but there is a drop in blood pres- sure levels [12]. Another mice experiment confirmed that Clock mutant male mice showed a decrease in blood pressure and heart rate, while also showing lower plasma aldosterone levels [37]. In contrast, Nakashima et al. [15] reported that Clock mutant mice showed reduced expression of ATP1B1, a gene encoding the $\beta 1$ subunit of $\mathrm{Na}^{+}$/ $\mathrm{K}^{+}$ATPase, causing increased blood pressure. In addition, the dysfunction of the circadian function can induce angiotensin II-dependent hypertension in mice [33]. Therefore, it is reasonable to believe that Clock plays an important role in the regulation of hypertension by the human kidney system. This process may involve the clock gene upregulating the expression of intercellular adhesion molecule-1, promoting the adhesion of monocytes to endothelial cells, and causing vascular inflammation [38]. In the current study, we did not observe relationships between Clock expression and blood pressure which may be attributable to the relatively small sample size.

Our results should be interpreted in the context of potential limitations. First, Kurbatova et al. [6] analyzed the RNA of oral epithelial cells in 34 hypertensive patients and found a general trend of downregulation of Arntl transcription levels and upregulation of Per1 expression 
from 9:00 a.m. to 5:00 p.m. We could not collect peripheral blood samples from participants at different time points, making it impossible to compare the relationship between rhythm changes and hypertension. Second, our study employed a case-control design; therefore, we could not determine the causal relationship between the Arntl mRNA expression levels and hypertension. Third, we did not collect the characteristics of patients' blood pressure, which limited the analysis of the relationship between genes and dipper/nondipper hypertension.

\section{Conclusions}

In sum, the levels of Arntl mRNA expression in PBMCs were significantly lower in hypertension patients than those in the control group in the female subjects. The results of our study emphasize the need for further investigation on the relationship between circadian clock genes and hypertension.

\section{Acknowledgments}

The authors gratefully acknowledge all of the participants in this study.

\section{Statement of Ethics}

The study procedure was approved by the Scientific Research Institutional Review Board of Wannan Medical College Yijishan Hospital (No. 32 [2018]) and was conducted in accordance with the Declaration of Helsinki. Written informed consent was obtained from all the participants.

\section{Conflict of Interest Statement}

The authors have no conflicts of interest to declare.

\section{Funding Sources}

This work was supported by the Key Projects of Anhui Provincial Department of Education (No. KJ2019A0404 and No. KJ2019A0405), National Natural Science Foundation of China (Grant Nos. 81874280 and 81673266), the Fifth Batch of Talents Selected under the Special Support Plan in Anhui Province (No. T000516), and the Natural Science Foundation of Anhui Province (1808085MH297). The funding body had no role in study design, data collection, analysis, interpretation of data, and preparation of the manuscript.

\section{Author Contributions}

Y.Y. and Z.F contributed to study concept and design. Z.F., Y.C., L.Z., W.C., Y.J., and Y.Y. contributed to subjects' collection. L.Z. and Y.J. contributed to acquisition and analysis of data. The drafting and writing of the manuscript was done by Z.F. and L.Z. The revision of the manuscript was done by Y.Y. and Y.C. All authors approved the final manuscript.

\section{Data Availability Statement}

The datasets analyzed in the present study are available from the corresponding author upon reasonable request.

\section{References}

1 Kunes J, Zicha J. The interaction of genetic and environmental factors in the etiology of hypertension. Physiol Res. 2009;58(Suppl 2): S33-41.

2 Lim SS, Vos T, Flaxman AD, Danaei G, Shibuya K, Adair-Rohani H, et al. A comparative risk assessment of burden of disease and injury attributable to 67 risk factors and risk factor clusters in 21 regions, 1990-2010: a systematic analysis for the Global Burden of Disease Study 2010. Lancet. 2012;380(9859): 2224-60.

3 Collaborators GBDCoD. Global, regional, and national age-sex-specific mortality for 282 causes of death in 195 countries and territories, 1980-2017: a systematic analysis for the Global Burden of Disease Study 2017. Lancet. 2018;392(10159):1736-88.
4 Kolomeichuk SN, Makeeva IV, Topchieva LV, Korneva VA, Nemova NN. [Association of T3111C polymorphism in $3^{\prime}$-untranslated region of the CLOCK gene with the risk of essential arterial hypertension and coronary artery disease in the Russian population Karelia]. Genetika. 2011;47(10):14115.

5 Peng Y, Woon, Kaisaki PJ, José BA, Marie-Thérèse B, Levy JC, et al. Aryl hydrocarbon receptor nuclear translocatorlike (BMAL1) is associated with susceptibility to hypertension and type 2 diabetes. Proc Natl Acad Sci U S A. 2007;104(36): 14412-7.

6 Kurbatova IV, Topchieva LV, Korneva VA, Kolomeichuk SN, Nemova NN. Expression of circadian rhythm genes CLOCK, BMAL1, and PER1 in buccal epithelial cells of patients with essential arterial hypertension in dependence on polymorphic variants of CLOCK and BMAL1 genes. Bull Exp Biol Med. 2014; 157(3):360-3.

7 Yu R, Tian L, Ding Y, Gao Y, Li D, Tang Y. Correlation between inflammatory markers and impaired circadian clock gene expression in type 2 diabetes mellitus. Diabetes Res Clin Pract. 2019;156:107831.

8 Albrecht U. The circadian clock, metabolism and obesity. Obes Rev. 2017;18 Suppl 1(1): 25-33.

9 Xie Z. RNA-sequencing analysis reveals Ltheanine regulating transcriptional rhythm alteration in vascular smooth muscle cells induced by dexamethasone. J Agric Food Chem. 2019;67(19):5413-22. 
10 Herichova I, Mravec B, Stebelova K, Krizanova $\mathrm{O}$, Jurkovicova $\mathrm{D}$, Kvetnansky $\mathrm{R}$, et al. Rhythmic clock gene expression in heart, kidney and some brain nuclei involved in blood pressure control in hypertensive TGR(mREN-2)27 rats. Mol Cell Biochem. 2007;296(1-2):25-34.

11 Kimura Y, Honda M, Sasaki R, Yumioka T, Iwamoto $\mathrm{H}$, Tsounapi $\mathrm{P}$, et al. Correction: the circadian rhythm of bladder clock genes in the spontaneously hypersensitive rat. PLoS One. 2019;14(12):e0227321.

12 Zuber AM, Centeno G, Pradervand S, Nikolaeva S, Maquelin L, Cardinaux L, et al. Molecular clock is involved in predictive circadian adjustment of renal function. Proc Natl Acad Sci U S A. 2009;106(38):16523-8.

13 Douma LG, Solocinski K, Holzworth MR, Crislip GR, Masten SH, Miller AH, et al. Female C57BL/6J mice lacking the circadian clock protein PER1 are protected from nondipping hypertension. Am J Physiol Regul Integr Comp Physiol. 2019;316(1):R50-8.

14 Anea CB, Zhang M, Stepp DW, Reed G, Guy $\mathrm{R}$, Fulton DJ, et al. Vascular disease in mice with a dysfunctional circadian clock. Circulation. 2009;119(11):1510-7.

15 Nakashima A, Kawamoto T, Noshiro M, Ueno T, Doi S, Honda K, et al. Dec1 and CLOCK regulate $\mathrm{Na}(+) / \mathrm{K}(+)$-ATPase beta 1 subunit expression and blood pressure. Hypertension. 2018;72(3):746-54.

16 Li GY, Wang H, Chen H. Association of insulin resistance with polymorphic variants of Clock and Bmall genes: a case-control study. Clin Exp Hypertens. 2020;42(4):371-5.

17 Englund A, Kovanen L, Saarikoski ST, Haukka J, Reunanen A, Aromaa A, et al. NPAS2 and PER2 are linked to risk factors of the metabolic syndrome. J Circadian Rhythms. 2009; 7:5.

18 Leu HB, Chung CM, Lin SJ, Chiang KM, Yang $\mathrm{HC}$, Ho HY, et al. Association of circadian genes with diurnal blood pressure changes and non-dipper essential hypertension: a genetic association with young-onset hypertension. Hypertens Res. 2015;38(2):155-62.

19 Cohen MC, Rohtla KM, Lavery CE, Muller JE, Mittleman MA. Meta-analysis of the morning excess of acute myocardial infarction and sudden cardiac death. Am J Cardiol. 1997; 79(11):1512.
20 Elliott WJ. Circadian variation in the timing of stroke onset: a meta-analysis. Stroke. 1998; 29(5):992-6.

21 Thosar SS, Butler MP, Shea SA. Role of the circadian system in cardiovascular disease. J Clin Invest. 2018;128(6):2157-67.

22 Woon PY, Kaisaki PJ, Bragança J, Bihoreau MT, Levy JC, Farrall M, et al. Aryl hydrocarbon receptor nuclear translocator-like (BMAL1) is associated with susceptibility to hypertension and type 2 diabetes. Proc Natl Acad Sci U S A. 2007;104(36):14412-7.

23 Diabetes Genetics Initiative of Broad Institute of Harvard and MIT, Lund University, and Novartis Institutes of BioMedical Research; Saxena R, Voight BF, Lyssenko V, Burtt NP, de Bakker PIW, et al. Genome-wide association analysis identifies loci for type 2 diabetes and triglyceride levels. Science. 2007; 316(5829):1331-6.

24 Ando H, Ushijima K, Kumazaki M, Takamura T, Yokota N, Saito T, et al. Influence of age on clock gene expression in peripheral blood cells of healthy women. J Gerontol A Biol Sci Med Sci. 2010;65(1):9-13.

25 Quintela T, Sousa C, Patriarca FM, Gonçalves I, Santos CR. Gender associated circadian oscillations of the clock genes in rat choroid plexus. Brain Struct Funct. 2015;220(3):125162.

26 Vida B, Hrabovszky E, Kalamatianos T, Coen CW, Liposits Z, Kalló I. Oestrogen receptor alpha and beta immunoreactive cells in the suprachiasmatic nucleus of mice: distribution, sex differences and regulation by gonadal hormones. J Neuroendocrinol. 2008; 20(11):1270-7.

27 Sellix MT, Murphy ZC, Menaker M. Excess androgen during puberty disrupts circadian organization in female rats. Endocrinology. 2013;154(4):1636-47.

28 Quintela T, Gonçalves I, Carreto LC, Santos MA, Marcelino H, Patriarca FM, et al. Analysis of the effects of sex hormone background on the rat choroid plexus transcriptome by cDNA microarrays. PLoS One. 2013;8(4): e60199.
29 Colafella KMM, Denton KM. Sex-specific differences in hypertension and associated cardiovascular disease. Nat Rev Nephrol. 2018; 14(3):185-201.

30 Anea CB, Cheng B, Sharma S, Kumar S, Caldwell RW, Yao L, et al. Increased superoxide and endothelial NO synthase uncoupling in blood vessels of Bmall-knockout mice. Circ Res. 2012;111(9):1157-65.

31 Shang X, Pati P, Anea CB, Fulton DJ, Rudic RD. Differential regulation of BMAL1, CLOCK, and endothelial signaling in the aortic arch and ligated common carotid artery. J Vasc Res. 2016;53(5-6):269-78.

32 Douma LG, Holzworth MR, Solocinski K, Masten SH, Miller AH, Cheng KY, et al. Renal $\mathrm{Na}$-handling defect associated with PER1-dependent nondipping hypertension in male mice. Am J Physiol Renal Physiol. 2018; 314(6):F1138-44

33 Pati P, Fulton DJ, Bagi Z, Chen F, Wang Y, Kitchens J, et al. Low-salt diet and circadian dysfunction synergize to induce angiotensin II-dependent hypertension in mice. Hypertension. 2016;67(3):661-8.

34 Stow LR, Richards J, Cheng KY, Lynch IJ, Jeffers LA, Greenlee MM, et al. The circadian protein period 1 contributes to blood pressure control and coordinately regulates renal sodium transport genes. Hypertension. 2012; 59(6):1151-6.

35 Jankowich M, Choudhary G. Endothelin-1 levels and cardiovascular events. Trends Cardiovasc Med. 2020;30(1):1-8.

36 Marques FZ, Campain AE, Tomaszewski M, Zukowska-Szczechowska E, Yang YH, Charchar FJ, et al. Gene expression profiling reveals renin mRNA overexpression in human hypertensive kidneys and a role for microRNAs. Hypertension. 2011;58(6):1093-8.

37 Sei H, Oishi K, Chikahisa S, Kitaoka K, Takeda E, Ishida N. Diurnal amplitudes of arterial pressure and heart rate are dampened in Clock mutant mice and adrenalectomized mice. Endocrinology. 2008;149(7):3576-80

38 Gao Y, Meng D, Sun N, Zhu Z, Zhao R, Lu C, et al. Clock upregulates intercellular adhesion molecule- 1 expression and promotes mononuclear cells adhesion to endothelial cells. Biochem Biophys Res Commun. 2014;443(2): $586-91$ 